\title{
Prediction of Attendance to the "Law of 60 Days" in Breast Cancer Patients using Machine Learning Classifiers
}

\section{Sandra Gioia ${ }^{1,3,5 *}$, Renata Galdino ${ }^{2}$, Lucia Brigagão ${ }^{2}$, Antonio Valadares ${ }^{3}$, Fernando Secol ${ }^{3}$, Sandra San $\mathrm{Miguel}^{4}$, Alexandra Bukowski $^{5}$, Lindsay Krush ${ }^{5}$ and Paul Goss ${ }^{5}$}

${ }^{1}$ Brazilian National Cancer Institute (INCA), Rio De Janeiro, Brazil

${ }^{2}$ State Secretary of Health, Rio De Janeiro, Brazil

${ }^{3}$ Israelita Albert Einstein Hospital, São Paulo, Brazil

${ }^{4}$ National Cancer Institute, Washington DC, USA

${ }^{5}$ Global Cancer Institute, Massachusetts General Hospital Cancer Center, Harvard

Medical School, Boston, Massachusetts, USA

*Corresponding Author: Sandra Gioia, Brazilian National Cancer Institute

(INCA), Rio De Janeiro, Brazil

DOI: $10.31080 /$ ASCB.2020.04.0209
Received: January 17, 2020

Published: February 11, 2020

(C) All rights are reserved by Sandra Gioia., et al.

\begin{abstract}
An applied study was conducted on how the use of machine learning techniques can help in the process of identifying compliance with the "Law of 60 Days", which states that all patients with cancer within the public system must initiate the treatment within 60 days after the diagnosis of cancer. Within the Patient Navigation Program (PNP) for breast cancer in Rio de Janeiro, the study aims to construct a model that accurately predicts whether or not a patient meets the period established in the Law. From August 2017 to May 2018, 105 patients aged 33 - 80 years (mean 59 years) were recruited for navigation. Patient Navigator (NP) applied questionnaires to collect clinical, psychosocial, and patient satisfaction information. The follow-up was by phone, email, or text message. For the development of the statistical analysis, three learning models were used: AdaBoost, Decision Tree and Gaussian NB. AdaBoost learning model had superior results in relation to accuracy and f-score ( 0.8889 and 0.8333 , respectively) and with good performance in relation to the prediction times. We identified 38 important attributes that contribute $95 \%$ of the importance of all the attributes present in the data. We identified 38 important attributes for compliance with the Law, which simplifies the information required for model learning. In the Brazilian context, the PNP may represent an opportunity to adequately implement existing legislation and, as such, would have great potential for integration into federal, state, and local health systems.
\end{abstract}

Keywords: Patient Navigation; Breast Neoplasms; Barriers; Health Systems; Machine Learning

\section{Introduction}

By 2025 , estimates suggest that $50 \%$ of the new cases and $60 \%$ of cancer-related deaths may occur in the developing countries [1]. In countries such as the United States of America (USA), the United Kingdom, France, and Australia, there was a decline in mortality in the last two decades, while in Latin America, an increase in mortality related to cancer was seen in the same period. In general, the survival rate in Latin American countries is, in average, 20\% below that of European countries or the USA [2].

Breast cancer is a major public health problem worldwide. In 2016, it was the second most prevalent malignant neoplasm, with about 2 million new cases and one of the main causes of cancerrelated death, with about 626,000 deaths worldwide [3]. 
In Brazil, breast cancer is the most common type of cancer and the leading cause of cancer-related death among women. In 2015, 15,403 cancer-related deaths were registered in the country, and 59,700 new cases are estimated for 2018 [4,5]. Many patients face barriers to accessing cancer treatment in the country, leading to delays in the diagnosis and treatment. Therefore, patients begin treatment at an advanced cancer stage, subsequently leading to higher mortality rates. In low- and middle-income countries, the long delays to diagnose and treat the disease often lead to the clinical progression of cancer. In the USA, $60 \%$ of the cases of breast cancer are diagnosed in the early stage of the disease, while in Brazil this is true for only $20 \%$ of the diagnoses [6].

Acknowledging the negative impact of this situation, in 2012, the Brazilian government decreed the Law No. 12.732/12 of the Ministry of Health, or the "Law of 60 Days". This law establishes that patients who use the public health system should be treated for any type of cancer within 60 days after the definite diagnosis [7]. Right after the "60-Day Law" was promulgated, the Cancer Information System (Sistema de Informação de Câncer, SISCAN) was adopted to monitor the implementation of the Law, by means of the treatment screening, medical appointments, and diagnostic exams, with goals and indicators for future actions in cancer control [8]. However, even years after the law's implementation, a considerable number of patients still do not receive treatment in a timely manner. The SISCAN was not effectively used and the innovative solutions are necessary to guarantee that the law be implemented appropriately. Research conducted by representatives of 59 public health institutions all over Brazil showed that the SISCAN is being used in only one quarter of the Brazilian municipalities, and about $1 \%$ of the total cases of cancer were registered in the system since July 2014, almost two years after the disclosure of this right [9]. Data collected in 239 hospitals throughout Brazil showed that almost $40 \%$ of the patients with breast cancer were not able to begin treatment within the period of 60 days [9]. The statistics vary considerably according to the region, and the state of Rio de Janeiro reports that more than $90 \%$ of the women do not begin treatment within the mandatory deadline of 60 days [9].

In this context, Patient Navigation Program (PNP), "a coordinated process of individualized assistance that is offered to patients to overcome barriers in the access to care and treatment in a timely manner, as well as to quality in complex health systems", may po- tentially enable the adequate application of this Federal Law [10]. PNP has been successful among the poor population in the USA, but its global implementation has proven to be limited. PNP has the potential to reduce the barriers of the health system and support the respect to the "60-Day Law" in Brazil, which could improve the results of women with breast cancer in Rio de Janeiro [11].

The field of study interested in the development of computer algorithms to transform data into intelligent action is known as machine learning. This field was originated in an environment in which the data available, the statistical methods and the technological power have evolved quickly and simultaneously. Data growth required an additional computational power, which has encouraged the development of statistical methods, to analyze broad data sets. This has created an advance cycle that allows for the collection of larger and more interesting data [12].

The Machine Learning algorithms may be divided into two main groups: supervised learning, used to build predictive models, and unsupervised learning, used to build descriptive models. A predictive model is used for tasks that involve, as the name suggests, the prediction of a value using other values in the data set. In this sense, the learning algorithm tries to discover and model the relationship among the dependent variable (target or response variable, which is being predicted) and the other independent variables [12].

The supervised learning algorithms can be grouped into regression and classification problems. In the classification, which is the object of this work, the output variable is obtained by means of a category, such as: "yes" or "no"; "high", "medium" or "low"; "ill" or "healthy". In the regression algorithms, the output variable is a numerical/continuous value, such as income, test results, item counting. The regression methods are widely used for prediction, as they quantify in exact terms the association between the inputs and the output variable, including the magnitude and the uncertainty of the relationship [12].

\section{Material and Methods}

Place of study and data source The patients were selected in the Diagnostic and Image Center in the state of Rio de Janeiro, known as Rio Imagem. Approximately 4,000 mammographies are performed per month among women from 92 municipalities that are users of the Unified Health System (Sistema Único de Saúde, SUS) in the state of Rio de Janeiro. 
In the case of the biopsies performed at Rio Imagem, all fragments are sent to the laboratory of the State Health Secretary, and the results are sent directly to Rio Imagem, where the patient will receive the report at the reception room. However, there is no supervision to know whether the patient will be referred for treatment in a specialized place. That is, the patient is responsible for searching for the appropriate center to begin treatment using the existing network of treatment centers. The introduction of PN can be an alternative for this gap in the breast cancer patient care.

The study metrics

The metrics collected were divided into two parts

Main Questionnaires - General information gathering about the patient characteristics. These questionnaires were designed for this study:

- $\quad$ Data of the patient population: Measured by the "Registration Questionnaire" or "Reason for Refusing to Fill in the Form", in order to collect demographic information about the population of patients that receive navigation, as well as understand why some patients cannot consent to being navigated.

- Dates and reference clinical information: Measured by the "Record of Clinical Dates and Information Forms" to register relevant clinical information, such as cancer type and diagnosis stage, and to calculate clinical intervals, such as time-to-treatment resolution.

- Work flow of the patient navigator: Measured by the "Registration of navigation screening" to understand how the Patient Navigator (PN) works at its local environment; for example, trying to understand how long the PN takes to help each patient and which barriers are found more frequently.

- Patient satisfaction: Measured by the "Patient Satisfaction Survey", to guarantee that navigation is well received and considered to be useful by the patients and their families.

\section{Psychosocial interview}

More detailed information gathering about the patient's disease and her battles. Standard questionnaires are used to measure different aspects of cancer treatment. They were specifically designed for the Latin population and are internationally and nationally used:
- Sociodemographic Ladder.

- Life Experience Survey.

- $\quad$ Perceived Efficacy in Patient-Physician Interactions.

- Charlson Score.

- Health Behavior Change.

- $\quad$ FACT-G.

- FACT-B.

- Level of Distress.

- Worry Interface.

- $\quad$ Self-Efficacy.

- Conclusion.

PN eligibility criteria

- Social assistant or healthcare provider with knowledge of the Regulation System of the city of Rio de Janeiro (SISREG) and of the State of Rio de Janeiro (SER).

- $\quad$ Experience with patients with breast cancer.

- Communication skills in the local language (Portuguese).

- Availability to work on the PNP designed for Rio de Janeiro.

\section{PN training}

A complete and comprehensive program was coordinated at Rio Imagem. This program was previously designed according to the successful PNP studies in the USA and with the help of a PN consultant. The training program lasted 2 days and informed participants about the general principles of patient navigation and defense, as well as about specific goals of the study, protocols, and data collection.

\section{Responsibilities of the PN}

The general responsibilities of the PN, included but were not limited to:

- To guide patient through the health system.

- To help patients fill in insurance documents.

- To guide patients toward timely treatment.

- $\quad$ To identify local resources and support that the patients can use, such as transportation, children aid resources, etc.

- $\quad$ To help patients attend appointments at Rio Imagem and at reference centers. 
- To remind patients about future appointments.

- To facilitate communication between patients and healthcare providers.

- $\quad$ To certify that the information provided to the patient is clearly understood and help to answer any question regarding follow-up.

- To explain the end of the navigation to the patient.

Population of patients

Inclusion criteria

1. Female patients between 18 and 80 years old.

2. Appointment at a public care facility regarding a confirmed breast cancer.

3. Inclusion in the unified health system (SUS).

Exclusion criteria

1. Unable to provide necessary personal documents.

2. Patients with private health insurance.

3. Patients younger than 18 years old or older than 80 years old.

4. Patients that only need supportive care (survival prognosis of less than 6 months).

5. Terminally ill patients due to another disease (survival prognosis of less than 6 months).

6. Unsheltered people.

7. History of sexual abuse or alcoholism.

8. Patients that suffer major psychotic disorders or uncontrolled psychiatric disorders.

9. Mentally impaired patients.

10. Prisoner-patients.

\section{Sample size}

This study aimed to enroll 115 patients into the navigation program, a sample size $15 \%$ larger than necessary to account for loss to follow-up and incomplete data.

The size of the sample was calculated based on the "success criteria" of at least $70 \%$ of the patients with breast cancer beginning treatment in the period of 60 days. A past study on Rio de Janeiro ${ }^{9}$ showed that only $30 \%$ of the women with breast cancer begin treatment within 60 days. Therefore, we hope to improve this number by $40 \%$, to achieve the success criteria of $70 \%$ or more. Finding a difference of $40 \%$ requires that 100 patients are navigated to achieve a statistical power of $80 \%$ and a significance level of 0.05 .

\section{Contact frequency}

The navigator should contact the patient at least once a week. If a direct contact with the patient occurs, it is considered a valid contact.

\section{End of navigation}

The navigation process will end for a patient, once she begins her first treatment course for breast cancer.

\section{Follow-up loss}

A patient will be considered "lost to follow-up" in the study after the navigator has tried to make 3 calls ( 1 call per week), has sent a written letter, and has made 3 additional calls ( 1 call per week after the letter has been sent), and has not received an answer from the patient. At this point, the navigator closes the file of this patient and labels her as "loss to follow-up".

\section{Statistical analysis}

To develop the analysis, the following steps were performed:

- Selection, collection, and data exploration.

- Preprocessing of thedatabases:

- Before the data could be used as an input for the learning algorithms, an evaluation of the treatment needs was performed, as well as the database design and restructuring.

- The necessity of transforming the main deviations of the variables with continuous data was also evaluated, in case the registrations of the same attribute have inconsistent values.

- Another transformation required was the normalization of the scale of numerical attributes, to guarantee that each attribute was treated with the same weight during the application of supervised learning.

- Conversion of categorical data in numbers: Learning algorithms receive numerical inputs, which requires that the categorical attributes (sex, educational background, etc.) be converted.

- Data shuffling and division in training sets and tests through a crossed validation methodology. 
- Evaluation of the model performance:

- $\quad$ Tests of 3 supervised learning algorithms and naive predictor.

- Accuracy, precision, sensitivity, and F1 score analysis.

- $\quad$ Creation of the training and prediction process:

- Evaluation of the performance of the models chosen, so as to train the models using data sets of several sizes for training, in addition to predict the data tests. Therefore, it will be possible to calculate the total time of prediction, as well as the accuracy and the F-score for both data sets (training and tests).

- Initial validation of the model, with different sizes of data sets for training (for example: $1 \%, 10 \%$ and $100 \%$ of the data)

- Selection of the best supervised learning model to be used in the test data.

- Final validation of the model: Refinement of the model selected, in order to obtain better results, and comparison between the results of the optimized and non-optimized model.

- Evaluation of the attribute relevance to determine which variables have a greater power of prediction. Thus, with less attributes to be trained, training and prediction are expected to have reduced execution time and, consequently, a lower cost.

\section{Results}

Between August 2017 and May 2018, 105 patients with ages between 33 - 80 years old (mean of 59 years old) were recruited

for the PNP. Eight patients were excluded because of follow-up loss. All patients were female, SUS users, lived in urban areas and spoke Portuguese. Among the 98 patients included in this analysis, twenty-three per cent (23\%) of the patients were younger than 50 years old. Patients presented with stage 0 (4\%), I-IIA (38\%), IIB-IIIB (48\%) and IV (5\%). These included barriers to compliance with the law: fear and fatalistic thoughts (99\%), financial burden (79\%), uncoordinated health care (76\%), attitudes towards providers (75\%), duplicity of pre-treatment exams (52\%), patient-provider communication (52\%), transport (42\%), scheduling (24\%), and queues for surgical treatment (12\%). PNP had $100 \%$ patient satisfaction and in $52 \%$ of the cases it helped the patients to start treatment within the period established by law.

Data selection, collection and exploration

In this stage, the following steps were taken:

- Consolidation of the databases (Common and Base Questionnaires) in only one base, totaling 293 original variables for analysis

- Identification and treatment of the variables with missing values, constant values ( 0 , for example) or high cardinality

- Analysis of the correlation among the variables

- Initial exploration of the data (variables with numerical data) shown in Figure 1.

- Correlation matrix among attributes for the columns with numerical values.
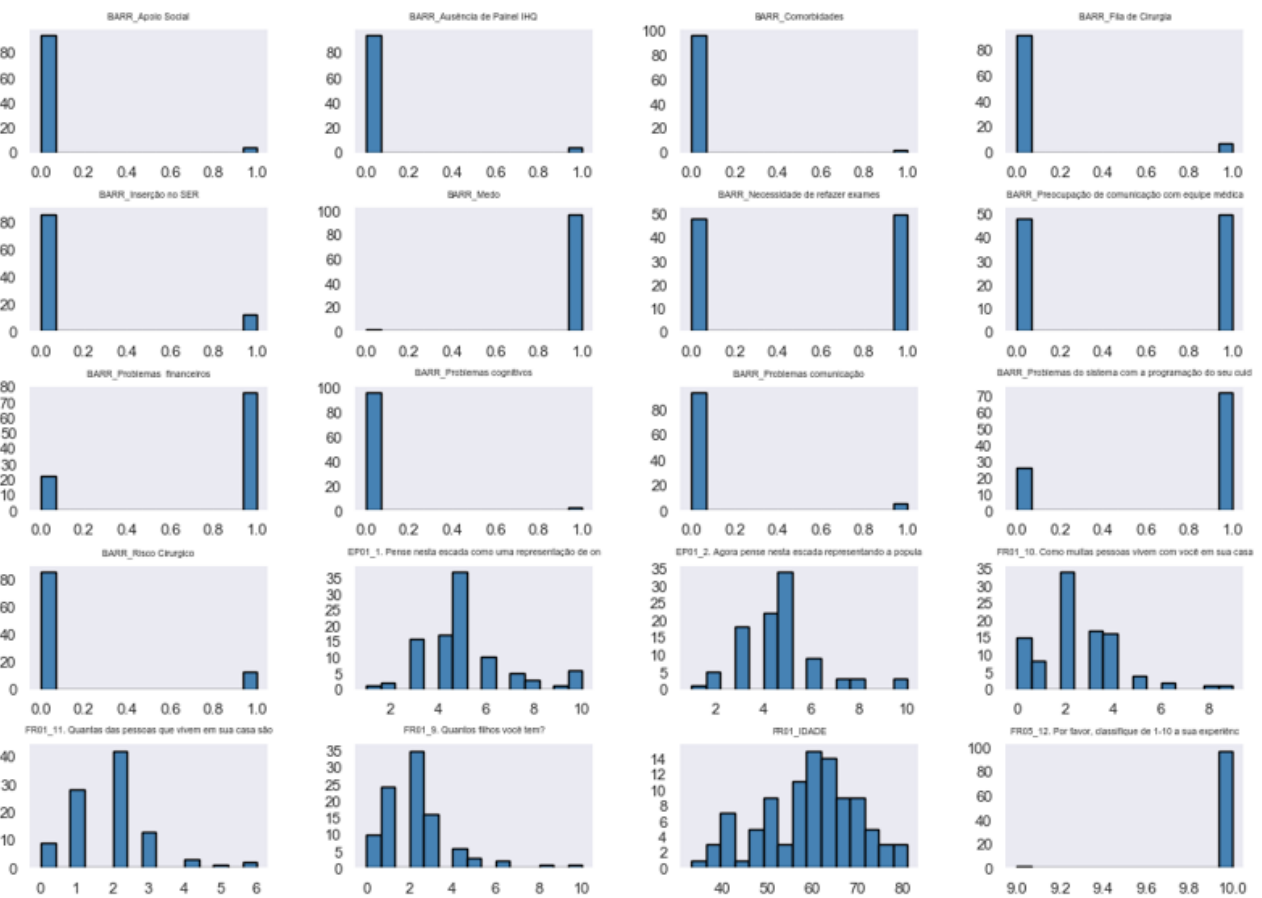

Figure 1: Initial exploration of the data (variables with numerical data).

Citation: Sandra Gioia., et al. "Prediction of Attendance to the "Law of 60 Days" in Breast Cancer Patients using Machine Learning Classifiers". Acta Scientific Cancer Biology 4.3 (2020): 16-28. 


\section{Database preprocessing}

- $\quad$ Normalization of the numerical scale attributes to guarantee that each attribute be treated with the same weight during the application of supervised learning.

- Conversion of categorical variables through the strategy of "one-hot encoding" -Conversion of categorical data into numerical data: Learning algorithms receive numerical inputs, which requires that the categorical attributes (sex, educational background) be converted. In this sense, the 219 variables that remained from the transformation process were converted into 890 variables after the application of the one-hot encoding methodology.

- Data shuffling and division in training and test sets through crossed validation methodology: With all the category variables as numerical attributes and all numerical attributes normalized, the data were divided into training and test sets [due to a small amount of observations (98 observation), the cross-validation technique was used to extract training and test data)];

\section{Implementation}

In this step, the evaluation of the model performance was conducted, considering the following steps:

- Tests of 3 supervised learning algorithms and naive predictor.

- Accuracy, precision, sensitivity, and F1 score analysis.

\section{Metricsused}

- Accuracy measures how often the classifier makes the correct prediction. It is the proportion between the number of correct predictions and the total number of predictions (the number of tested registrations).

- Precision informs which is the proportion between:

[True positives /(True positives + False positives)]

- Recall(sensitivity) informs the proportion between:

[True positives / (True positives + False negatives)]
- $\quad$ F1 score is calculated through the mean (harmonic mean) of the precision and recall values. This score can vary between 0 and 1, 1 being the best result possible for F1 score (we consider the harmonic mean because we are dealing with proportions).

Using the accuracy as a metric to assess the performance of a model is an adequate parameter. Therefore, the capacity of the model to predict with precision those that comply with the 60-Day Law is more important than performing the recall of these individuals. The F-beta score formula will also be used as a metric that considers both precision and recall.

For the Naive Predictor, the following parameters were calculated: Naive Predictor: [Accuracy score: 0. 4796, F-score: 0. 5353].

After this step, the training and prediction processes were created to evaluate the performance of the models chosen, in order to train models using several sizes of data set for training, in addition to make predictions in the test data. Thus, it was possible to calculate the total time of prediction, as well as the accuracy and the F-score for both data sets (training and tests).

Therefore, the following activities were performed:

- Importation of the three supervised learning models chosen.

- Initialization of the three models and storage in the "clf_A", "clf_B", and "clf_C" variables.

- Calculation of the number of registrations equivalent to $1 \%, 10 \%$ and $100 \%$ of the training data.

- Storage of the values in "amostra_1", "amostra_10", and "amostra_100" respectively.

- Initial validation of the model, with different sizes of training data sets $(1 \%, 10 \%$ and $100 \%$ of the data)

- $\quad$ Selection of the best supervised learning model to use in the test data.

- $\quad$ The following outputs were generated (Figure 2): Model - Classes: Comply with the 60-Day Law: Yes=1 / No = 0). 
In this sense, 38 (thirty-eight) attributes were identified to contribute with $95 \%$ of the importance of all attributes present in the data (of a total of 902 attributes assessed, after the consolidation and treatment of all bases analyzed), indicating that a reduction of the attributes and simplification of the information required for the model learning can be performed.

In addition, there is the scenario presented in Table 2.

Thus, to model the factors that influence the compliance with the 60-Day Law, the attributes are listed in Table 3.

\begin{tabular}{|c|c|}
\hline $\begin{array}{c}\text { Number of Attributes } \\
\text { Required for Modeling } \\
\text { (Total of Attributes: 902) }\end{array}$ & \% of Importance \\
\hline 40 & $100 \%$ \\
\hline 38 & $95 \%$ \\
\hline 30 & $80 \%$ \\
\hline 20 & $60 \%$ \\
\hline 15 & $50 \%$ \\
\hline
\end{tabular}

Table 2: Number of Attributes Required for Modeling and Percentage of Importance of Attributes.

\begin{tabular}{|c|c|c|c|c|}
\hline \multirow{2}{*}{$\begin{array}{l}\text { Individual } \\
\text { Contribution }\end{array}$} & \multirow{2}{*}{$\begin{array}{l}\text { Accumulated- } \\
\text { Contribuition }\end{array}$} & \multicolumn{3}{|c|}{ Combined Variable(Questionnaire+Issue+Response) } \\
\hline & & Questionnaire & Issue & Response \\
\hline $6.00 \%$ & $6.00 \%$ & $\begin{array}{l}\text { Form 3_Datas Clínicas } \\
\text { (Responses) }\end{array}$ & TNM clinicalstaging & IIIB \\
\hline $6.00 \%$ & $12.00 \%$ & Barriers & $\begin{array}{l}\text { Problems of the system with } \\
\text { the programming of your } \\
\text { healthcare }\end{array}$ & - \\
\hline $4.00 \%$ & $16.00 \%$ & $\begin{array}{l}\text { Form 1_Questionário de } \\
\text { Inscrição } \\
\text { (RegistrationForm) }\end{array}$ & $\begin{array}{l}\text { 12. Does the cost of people liv- } \\
\text { ing with you depend solely on } \\
\text { your personal income? }\end{array}$ & No \\
\hline $4.00 \%$ & $20.00 \%$ & $\begin{array}{c}\text { EP 8_ FACT-B (Breast } \\
\text { cancer) }\end{array}$ & 5. I feel bothered by hair loss & 2 (More orless) \\
\hline $4.00 \%$ & $24.00 \%$ & EP 7_FACT-G & $\begin{array}{l}\text { 7. I'm satisfied with my sexual } \\
\text { life }\end{array}$ & 3 (Prettymuch) \\
\hline $4.00 \%$ & $28.00 \%$ & EP 7_FACT-G & 4. I acceptmydisease & 1 (A little bit) \\
\hline $4.00 \%$ & $32.00 \%$ & EP 7_FACT-G & 1. I'm out of energy & 0 (Notatall) \\
\hline $4.00 \%$ & $36.00 \%$ & Barriers & $\begin{array}{l}\text { Necessity of performing the } \\
\text { exams again }\end{array}$ & - \\
\hline $2.00 \%$ & $38.00 \%$ & $\begin{array}{c}\text { Form 3_Datas Clínicas } \\
\text { (Responses) }\end{array}$ & progesterone receptor & No information \\
\hline $2.00 \%$ & $40.00 \%$ & $\begin{array}{c}\text { Form 3_Datas Clínicas } \\
\text { (Responses) }\end{array}$ & $\begin{array}{c}\text { What is the referral center for } \\
\text { treatment? }\end{array}$ & Darcy Vargas Hospital \\
\hline $2.00 \%$ & $42.00 \%$ & $\begin{array}{c}\text { Form 3_Datas Clínicas } \\
\text { (Responses) }\end{array}$ & Ki67 & No information \\
\hline $2.00 \%$ & $44.00 \%$ & $\begin{array}{l}\text { Form 3_Datas Clínicas } \\
\text { (Responses) }\end{array}$ & HER2 & Negative \\
\hline $2.00 \%$ & $46.00 \%$ & $\begin{array}{l}\text { Form 3_Datas Clínicas } \\
\text { (Responses) }\end{array}$ & TNM clinicalstaging & IV \\
\hline $2.00 \%$ & $48.00 \%$ & Form1_Registration Form) & AGE & - \\
\hline
\end{tabular}




\begin{tabular}{|c|c|c|c|c|}
\hline $2.00 \%$ & $50.00 \%$ & Form1_Registration Form) & $\begin{array}{l}\text { 3. How long does the patient } \\
\text { take to get to the clinic (Rio } \\
\text { Imagem) of his home by his } \\
\text { usual mode of transportation? }\end{array}$ & $<1$ hour \\
\hline $2.00 \%$ & $52.00 \%$ & Form1_Registration Form) & $\begin{array}{l}\text { 10. How many people live with } \\
\text { you in the same house? }\end{array}$ & - \\
\hline $2.00 \%$ & $54.00 \%$ & EP 11_Self-efficacy & $\begin{array}{l}\text { 7. To discuss openly with your } \\
\text { doctor about personal aspects } \\
\text { that are related to your disease }\end{array}$ & 3 (Thoroughly) \\
\hline $2.00 \%$ & $56.00 \%$ & EP 11_Self-efficacy & $\begin{array}{l}\text { 6. To ask the doctor about the } \\
\text { aspects of your disease that } \\
\text { worry you }\end{array}$ & 3 (Thoroughly) \\
\hline $2.00 \%$ & $58.00 \%$ & EP 11_Self-efficacy & $\begin{array}{l}\text { 21. Prevent fatigue from keep- } \\
\text { ing you from doing the things } \\
\text { you are interested in doing }\end{array}$ & 4 (Totallyconfident) \\
\hline $2.00 \%$ & $60.00 \%$ & EP 11_Self-efficacy & $\begin{array}{l}\text { 2. Have help from relatives and } \\
\text { friends to help me with things } \\
\text { I need (like taking care of my } \\
\text { house, buying, cooking, trans- } \\
\text { porting) }\end{array}$ & 4 (Totallyconfident) \\
\hline $2.00 \%$ & $62.00 \%$ & EP 11_Self-efficacy & $\begin{array}{l}\text { 2. Have help from relatives and } \\
\text { friends to help me with things } \\
\text { I need (like taking care of my } \\
\text { house, buying, cooking, trans- } \\
\text { porting) }\end{array}$ & 3 (Thoroughly) \\
\hline $2.00 \%$ & $64.00 \%$ & EP 11_Self-efficacy & 16. Avoid feeling alone & 3 (Thoroughly) \\
\hline $2.00 \%$ & $66.00 \%$ & $\begin{array}{c}\text { EP 8_FACT-B } \\
\text { (Breast cancer) }\end{array}$ & 9. I can feel myself a woman & 0 (Notatall) \\
\hline $2.00 \%$ & $68.00 \%$ & $\begin{array}{l}\text { EP 8_FACT-B } \\
\text { (Breast cancer) }\end{array}$ & $\begin{array}{l}\text { 6. I am concerned that other } \\
\text { members of my family may one } \\
\text { day have the same illness as me }\end{array}$ & 3 (Prettymuch) \\
\hline $2.00 \%$ & $70.00 \%$ & $\begin{array}{c}\text { EP 8_FACT-B } \\
\text { (Breast cancer) }\end{array}$ & 5. I feel bothered by hair loss & I don'tknow \\
\hline $2.00 \%$ & $72.00 \%$ & $\begin{array}{c}\text { EP 8_FACT-B } \\
\text { (Breast cancer) }\end{array}$ & 5. I feel bothered by hair loss & 4 (Very Much) \\
\hline $2.00 \%$ & $74.00 \%$ & $\begin{array}{l}\text { EP 8_FACT-B } \\
\text { (Breast cancer) }\end{array}$ & 5. I feel bothered by hair loss & 1 (A little bit) \\
\hline $2.00 \%$ & $76.00 \%$ & $\begin{array}{l}\text { EP 8_ FACT-B } \\
\text { (Breast cancer) }\end{array}$ & 4. I feel sexually attractive & 1 (A little bit) \\
\hline
\end{tabular}


Prediction of Attendance to the "Law of 60 Days" in Breast Cancer Patients using Machine Learning Classifiers

\begin{tabular}{|c|c|c|c|c|}
\hline $2.00 \%$ & $78.00 \%$ & $\begin{array}{c}\text { EP 8_FACT-B } \\
\text { (Breast cancer) }\end{array}$ & $\begin{array}{l}\text { 10. I feel pain in some regions } \\
\text { of my body }\end{array}$ & 2 (More orless) \\
\hline $2.00 \%$ & $80.00 \%$ & EP 7_FACT-G & $\begin{array}{l}\text { 6. I like the things I usually do } \\
\text { to have fun }\end{array}$ & 3 (Prettymuch) \\
\hline $2.00 \%$ & $82.00 \%$ & EP 7_FACT-G & 5. I sleep well & 1 (A little bit) \\
\hline $2.00 \%$ & $84.00 \%$ & EP 7_FACT-G & 4. I have pains & 2 (More orless) \\
\hline $2.00 \%$ & $86.00 \%$ & EP 7_FACT-G & 4. I accept my disease & 0 (Notatall) \\
\hline $2.00 \%$ & $88.00 \%$ & EP 7_FACT-G & 4. My family accepts my disease & 4 (Fully) \\
\hline $2.00 \%$ & $90.00 \%$ & EP 7_FACT-G & $\begin{array}{l}\text { 2. I'm satisfied with the way I } \\
\text { fight my disease }\end{array}$ & 2 (More orless) \\
\hline $2.00 \%$ & $92.00 \%$ & EP 7_FACT-G & $\begin{array}{l}\text { 2. I'm satisfied with the way I } \\
\text { fight my disease }\end{array}$ & 0 (Notatall) \\
\hline $2.00 \%$ & $94.00 \%$ & $\begin{array}{c}\text { EP 3_PEPPI (Perceived } \\
\text { efficacy in the relation- } \\
\text { ship between doctor and } \\
\text { patient) }\end{array}$ & $\begin{array}{l}\text { 3. How much are you confident } \\
\text { in your capacity to make the } \\
\text { doctor answer all your ques- } \\
\text { tions? }\end{array}$ & 3(Prettymuch) \\
\hline $2.00 \%$ & $96.00 \%$ & $\begin{array}{c}\text { EP 2_LES-10 (Question- } \\
\text { naire about life experience) }\end{array}$ & $\begin{array}{l}\text { 2. Impact on sleeping habits / } \\
\text { Did this event happen? }\end{array}$ & No \\
\hline $2.00 \%$ & $98.00 \%$ & Barriers & $\begin{array}{l}\text { Preoperative medical evalua- } \\
\text { tion }\end{array}$ & - \\
\hline $2.00 \%$ & $100.00 \%$ & Barriers & $\begin{array}{l}\text { Insertion in the SER regulation } \\
\text { system }\end{array}$ & - \\
\hline
\end{tabular}

Table 3: Factors influencing compliance with the 60 Day Law.

\section{Attribute selection}

From the table above, we can see that the 38 most important attributes contribute with $95 \%$ of the importance of all attributes present in the data, which indicates that the attributes can be reduced, and the information required can be simplified for the model learning. Figure 5 shows the procedure performed with the same model, trained with the same training data set, but only with the 38 most important attributes.

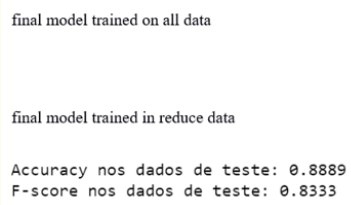

Figure 5: Confusion matrices according to the learning models used.
Based on the results above, a reduction in accuracy and in the fscore is observed when the attributes with representation of $95 \%$ of importance are used. Therefore, the 38 attributes found represent a significant reduction in dimensionality compared to the 902 variables used for modeling.

\section{Discussion}

Approaches focused on specific populations and with integral information allow the decision makers to understand the needs of each group and plan specific actions in order to improve the quality of the services provided [12].

The use of the patient navigator facilitates the appropriate and efficient use of services. It is a program that is considered an indicator of quality in several health services in the USA, Canada, and Europe, which is still not much studied in periphery countries. The navigator is a link between the patient and the system, the health 
professionals, and providers, which brings equity to the vulnerable population $[11,13]$.

Patient navigators are trained healthcare providers who facilitate the process of patients within the health system, helping them to overcome institutional, socioeconomic, and personal barriers to the access. They provide services such as scheduling diagnosis and follow-up appointments, which facilitates the referral to the health system. Additionally, navigators coordinate the communication between patients and health care providers. Patient navigators help patients receive medical care in a timely manner and reduce the delays in care and the loss to follow-up rates [11].

Although Brazil has made improvements regarding breast cancer prevention and control, the country continues to face high breast cancer incidence, late-stage diagnosis and high mortality rates. In Brazil, the breast malignant neoplasm is highly incident and is the main cause of cancer-related deaths among women. Barriers to accessing healthcare lead to delays in the diagnosis and treatment, consequently leading to advanced stage disease presentation and high mortality [14].

As part of the development of the statistical analysis in the databases, the refinement stage was aimed at obtaining better solutions, as well as comparing the results among the optimized and non-optimized model. The Grid Search was performed to optimize the entire training data set ('X_train' and 'y_train') by tuning at least one parameter, in order to verify whether it is possible to improve the previous metrics. Regarding the use of Grid Search with the Adaboost, significant changes were observed in the model regarding the Accuracy Score and the F-Score, except for the time of training+prediction, which was considerably longer than in the non-optimized model. It is worth mentioning that, when compared with the Naive Predictor, the results of the optimized model showed a considerable improvement.

In addition, the assessment of the attribute relevance was performed, in order to determine which variables, have a greater prediction power. Thus, with less attributes to train, training and prediction are expected to have a reduced time of execution and, consequently, less cost. In this sense, it was possible to verify that the 38 (thirty-eight) most important attributes contribute to more than $95 \%$ of the importance of all attributes present in the data (of a total of 902 attributes assessed, after the consolidation and treatment of all bases analyzed), which indicates that the attributes can be reduced and the required information can be simplified to learn the model.

The model found important variables that predict compliance with the 60 Day Law of patients diagnosed with breast cancer in the Rio Image. These variables facilitated compliance with the Law:

- $\quad$ Advanced staging (III and IV) due to the greater ease of starting systemic treatment.

- Proactively assist patients in the following barriers: system problems with health programming, need to retake exams, surgical risk consultations, and insertion in the SER.

- Treatment in a hospital outside the city of Rio de Janeiro Darcy Vargas Hospital in Rio Bonito.

- Absence of immunohistochemistry tests for progesterone receptor and Ki67.

- $\quad$ Receptor positive for HER2.

- $\quad$ Older patients.

- Social and financial support.

- Confidence in talking about illness and maintaining habitual life activities.

- Openness to communicate with attending physicians.

- Accept concerns about the side effects of treatment such as hair loss and body aches and maintaining sex life.

In this study, all patients declared that they did not know the next step after having received the diagnosis at Rio Imagem. Some mentioned that they would "keep the report in a drawer for some days until they could understand what was going on" and "...it seems to be a world-class thing...God bless your work!"

This last statement reminds us of the fact that this project started in a developed country to provide care to patients that had difficulty in reaching the breast cancer care and reached an extraordinary result of elevating the survival rate from $31 \%$ to $70 \%$ in the 1990s. This accomplishment has led PN to be recognized by the American Government since 2005, and today it is an indicator of quality of the services that provide oncology assistance in the USA [15]. 
PNP has shown us that navigation is an innovative solution to a complex problem in Brazil. We are talking about people and process management focused on patient care. Everybody is prompted to reflect about their work practices and be responsible for the care management of the patient with breast cancer, either in the micro, meso or macro management: from self-care, family and community care, care offered in services, care provided at care facilities, and policy formulation to the search for innovative financial instruments [14].

PNP is aimed at providing timely diagnosis and treatment our complex and fragmented SUS. It has the potential to offer dignity to health system users, eliminating barriers and bureaucracies with attention to the human being and not the disease itself, transforming the disease regulatory system into a patient follow-up system [14]. PN was responsible for the compliance of the "60-Day Law" in $52 \%$ of the cases, not reaching the project's target of $70 \%$. To comply with the 60-Day Law, the Rio de Janeiro Health System must be more transparent, and the optimization of financial and human resources should be carried out as soon as possible.

\section{Conclusion}

PNP Rio has not reached the success rate of $70 \%$ to comply with the Law, as intended (it reached 52\%). However, the barriers that the PN does not manage to overcome, such as the lack of human resources and medical supplies, were informed to the health authorities and to the hospital managers. Thirty-eight important attributes were identified, which simplifies the information required for the model learning.

This is an opportunity of discussing budget reallocation, by focusing on the use of scarce resources in the prevention and early treatment. In the Brazilian context, the PNP may represent an opportunity of implementing appropriately the existing legislation and, as such, it would have a great potential of integration in the federal, state, municipal and local health systems.

\section{Acknowledgements}

Ricardo Costa, Dell Inc., Brazil.

\section{Bibliography}

1. Bray F., et al. "Global estimates of cancer prevalence for 27 sites in the adult population in 2008". International Journal of Cancer 132.5 (2013):1133-1145.
2. Goss PE., et al. "Planning cancer control in Latin America and the Caribbean". The Lancet Oncology 14 (2013): 391-436.

3. Bray F., et al. "Global Cancer Statistics 2018: GLOBOCAN Estimates of Incidence and Mortality Worldwide for 36 Cancers in 185 Countries". CA: A Cancer Journal for Clinicians (2018): 1-31.

4. Instituto Nacional de Câncer (Brasil): Estatísticas do câncer: Mortalidade. http://www1.inca.gov.br/vigilância/ mortalidade.asp. Accessed June 11, 2018.

5. Instituto Nacional de Câncer (Brasil): Estimativa Incidência de câncer no Brasil (2018). http://www.inca.gov.br/estimativa/2018/sintese-de-resultados-comentarios.asp. Accessed June 11, 2018.

6. Unger-Saldãna K. "Challenges to the early diagnosis and treatment of breast cancer in developingcountries". World Journal of Clinical Oncology 5 (2014): 465-477.

7. Brasil. Presidência da República. Lei no. 12.732, de 22 de novembro de 2012. Dispõe sobre o primeiro tratamento de paciente com neoplasia maligna comprovada e estabelece prazo para seu início". Diário Oficial da União 23 nov. Seção I (2012): 1. http://www. planalto.gov.br/ccivil_03/_ato20112014/2012/lei/l12732. htm

8. Ministério da Saúde. Portaria no 3.394, de 30 de dezembro de Institui o Sistema de Informação de Câncer (SICAN) no âmbito do Sistema Único de Saúde (SUS) ". Diário Oficial da União 31 dez. Seção I (2013): 57-8. https://irhc.inca.gov.br/RHCNet/ jasper/ pdf on 04/22/2019. Accessed June 11, 2018.

9. Federação Brasileira de Instituições Filantrópicas de Apoio a Saúde da Mama: Pesquisa: A implementação da Lei dos 60 dias. http://www.femama.org.br/novo/arquivos/audiencia_ publica_pesquisa_60_dias.pdf

10. Bukowski A., et al. "The potential role of patient navigation in low- and middle-income countries for patients with cancer". JAMA Oncology 2 (2016): 994-995.

11. Bukowski A., et al. "Patient Navigation to Improve Access to Breast Cancer Care in Brazil". Journal of Global Oncology 5 (2017): 433-437.

12. Lantz B. "Machine Learning with R". Packt Publishing (2014). 
13. Harford J., et al. "Guideline Implementation for Breast Healthcare in Low- and Middle-Income Countries". CANCER Supplement 15.113 (2008): 2282-2296.

14. Gioia S. "Why is breast cancer early detection important?" Mastology 27.3 (2017): 173-175.

15. Naomi Ko., et al. "Can Patient Navigation Improve Receipt of Recommended Breast Cancer Care? Evidence from the National Patient Navigation Research Program". Journal of Clinical Oncology 32 (2014): 2758-2764.

\section{Assets from publication with us}

- Prompt Acknowledgement after receiving the article

- Thorough Double blinded peer review

- Rapid Publication

- Issue of Publication Certificate

- High visibility of your Published work

Website: https://www.actascientific.com/

Submit Article: https://www.actascientific.com/submission.php

Email us: editor@actascientific.com

Contact us: +919182824667 